\title{
Nationwide quality assessment of treatment for chronic obstructive pulmonary disease
}

\author{
Kyu Yean Kim ${ }^{1}$, Kwang Ha Yoo ${ }^{2}$, Hye Sook $\mathrm{Choi}^{3}$, Bo Yeon $\mathrm{Kim}^{4}$, Sang In $\mathrm{Ahn}^{4}$, Yon U. Jo \\ Chin Kook Rhee ${ }^{5} \wedge$
}

${ }^{1}$ Division of Pulmonary and Critical Care Medicine, Department of Internal Medicine, Uijeongbu St. Mary's Hospital, College of Medicine, The Catholic University of Korea, Gyeonggi-do, Uijeongbu, South Korea; ${ }^{2}$ Division of Pulmonary and Critical Care Medicine, Department of Internal Medicine, Konkuk University School of Medicine, Seoul, South Korea; ${ }^{3}$ Division of Pulmonary, Allergy and Critical Care Medicine, Department of Internal Medicine, Kyunghee University Hospital, Seoul, South Korea; ${ }^{4}$ Health Insurance Review \& Assessment Service, Wonju, South Korea; ${ }^{5}$ Division of Pulmonary, Allergy and Critical Care Medicine, Department of Internal Medicine, Seoul St. Mary's Hospital, College of Medicine, The Catholic University of Korea, Seoul, South Korea

Contributions: (I) Conception and design: CK Rhee, KH Yoo; (II) Administrative support: KH Yoo, BY Kim, SI Ahn, YU Jo, CK Rhee; (III) Provision of study materials or patients: HS Choi, CK Rhee; (IV) Collection and assembly of data: CK Rhee, KY Kim; (V) Data analysis and interpretation: CK Rhee, KH Yoo, BY Kim, SI Ahn, YU Jo; (VI) Manuscript writing: All authors; (VII) Final approval of manuscript: All authors.

Correspondence to: Chin Kook Rhee, MD, PhD. Division of Pulmonary, Allergy and Critical Care Medicine, Department of Internal Medicine, College of Medicine, Seoul St Mary's Hospital, The Catholic University of Korea, 222 Banpo-daero, Seocho-gu, Seoul 06591, South Korea. Email: chinkook77@gmail.com.

Background: Chronic obstructive pulmonary disease (COPD) requires careful ambulatory care. If treatment is effective, exacerbation and hospitalization can be preventable. Appropriate management is important; the disease prevalence is high, as is the demand on healthcare resources. Here, we have reported the results of nationwide quality assessment performed with the aims of improving patient management, reducing progression to severe status, and minimizing medical care expenses.

Methods: The Health Insurance Review and Assessment Service (HIRA) engaged in quality assessment three times from May 2014 to April 2017. Medical care institutions were evaluated in terms of the pulmonary function test (PFT), patient revisit, and inhaled bronchodilator prescription rates.

Results: The numbers of patients assessed were 141,782, 142,790, and 143,339 in years 1, 2, and 3, respectively; the numbers of medical care institutions assessed were 6,691, 6,722, and 6,470, respectively. The PFT implementation rates were $58.7 \%, 62.5 \%$, and $67.9 \%$ for years 1,2 , and 3 , respectively; these rates were highest for tertiary hospitals, followed by general and local hospitals, as well as primary healthcare clinics. The repeat visit rates were $85.5 \%, 92.1 \%$, and $85.0 \%$ for years 1,2 , and 3, respectively; these rates were highest for general hospitals, followed by local and tertiary hospitals, and primary healthcare clinics. The inhaled bronchodilator prescription rates were $67.9 \%, 71.2 \%$, and $76.9 \%$ for years 1,2 , and 3 , respectively; these rates increased with increasing hospital grade.

Conclusions: The PFT and inhaled bronchodilator prescription rates improved over the 3-year nationwide quality assessment period.

Keywords: Chronic obstructive pulmonary disease (COPD); assessment; quality

Submitted Feb 16, 2020. Accepted for publication Sep 15, 2020.

doi: $10.21037 /$ jtd-20-905

View this article at: http://dx.doi.org/10.21037/jtd-20-905

^ ORCID: 0000-0003-4533-7937. 


\section{Introduction}

Chronic obstructive pulmonary disease (COPD) is a major disease in South Korea. The prevalence of COPD among individuals aged over 40 years is $13.4 \%$, as demonstrated by the second Korean National Health and Nutrition Examination Survey (KNHANES II) (1). The associated medical costs were approximately 1,245 million USD in 2015: 0.09\% of the South Korean GDP (2). Moreover, according to the Statistics Korea, COPD was $8^{\text {th }}$ cause of death in 2018 (3). However, in spite of this burden, COPD is underdiagnosed and undertreated in South Korea. According to KNHANES II, among subjects who were confirmed as COPD by spirometry, only $2.4 \%$ reported having been diagnosed with COPD and $2.1 \%$ treated (1). Also, according to the analysis of Health Insurance Review and Assessment Service (HIRA) data, pulmonary function test (PFT) was not routinely performed and the prescription rate of inhaler was low (4). Adherence of inhaler was also very low in even high-grade COPD patients (5). In order to solve these problems, HIRA initiated nationwide quality assessment program since 2014. COPD requires careful ambulatory care. If treatment is effective, exacerbation and hospitalization are preventable. The COPD admission rate in South Korea averages 214.2 per 100,000; the average Organization for Economic Co-operation and Development rate is 189.8 per 100,000 (6). Appropriate management is important; the disease is common and the demand on healthcare resources is high.

HIRA hypothesize implement of nationwide quality assessment program will improve COPD management, especially in primary care clinic. For example, PFT ratio in primary and secondary care facilities were only $11.1 \%$ while $40.6 \%$ in tertiary (4). Percentage of use of long acting muscarinic antagonist (LAMA) in primary and secondary was $8.1 \%$ while $32.7 \%$ in tertiary (4). Here, we have reported the results of nationwide quality assessment performed with the aims of improving patient management, reducing progression to severe status, and minimizing medical care expenses.

\section{Methods}

\section{Study design}

The HIRA initiated quality assessment in 2014 and has performed annually. In this study, we have integrated and summarized key results of three years' assessments (2014, 2015, and 2016). First assessment period is from
May 2014 to April 2015. Second is from May 2015 to April 2016 and third is May 2016 to April 2017. HIRA has reviewed all the claim data which was generated during the assessment period and identified COPD patients. Quality assessment was performed for the hospitals who managed COPD patients during each assessment period. All claim data during each one year was analyzed. All patients were followed for one year (each assessment period).

\section{Procedure}

HIRA has annually analyzed all claim data from South Korea and enrolled all hospitals that managed COPD patients regardless of the type. COPD was identified by following working definition. The inclusion criteria were: (I) age $\geq 40$ years; (II) ICD-10 codes J43-44 (except J43.0) for primary or first subsidiary diagnosis; (III) (a) visit(s) to (a) medical care institution(s) during the assessment period; and either (IV) outpatient clinic prescription of COPD medication more than twice or (V) a history of admission while using a systemic corticosteroid followed by outpatient clinic prescription of COPD medication more than once. This COPD definition has been validated and used in several previous studies (4,5,7-17). Asthma was not excluded in this study. Entire medical facilities in South Korea were screened and any medical facilities where COPD patients were managed were enrolled in quality assessment.

\section{Variables definition}

COPD medications included short-acting beta-2 agonists, short-acting muscarinic antagonists, combination shortacting beta- 2 agonists and short-acting muscarinic antagonists, long-acting muscarinic antagonists, longacting beta- 2 agonists, combination long-acting beta- 2 agonists and long-acting muscarinic antagonists, inhaled corticosteroid, combination inhaled corticosteroid and long-acting beta-2 agonist, a phosphodiesterase 4 inhibitor, methyl xanthine derivatives, and systemic bronchodilators.

Medical care institutions were evaluated in terms of the PFT implementation, revisit, and inhaled bronchodilator prescription rates. The PFT implementation rate was the proportion of patients tested more than once annually during each of the 3 years. The revisit rate was the proportion of patients with COPD who visited the same medical care institution more than three times during the assessment period. COPD visit was defined by the presence 
Table 1 Number of patients with chronic obstructive pulmonary disease (COPD) treated according to grade of medical institution

\begin{tabular}{lcccc}
\hline Year & Tertiary hospital (\%) & General hospital (\%) & Primary healthcare clinic (\%) & Total \\
\hline First & $36,259(25.6)$ & $55,189(38.9)$ & $42,595(30.0)$ & 141,782 \\
Second & $37,720(26.4)$ & $57,715(40.4)$ & $40,026(28.0)$ & 142,790 \\
Third & $40,911(28.5)$ & $59,501(41.5)$ & $36,428(25.4)$ & 143,339 \\
\hline
\end{tabular}

of ICD-10 codes J43-44 (except J43.0) for primary or first subsidiary diagnosis in outpatient claim data. The inhaled bronchodilator prescription rate was the proportion of patients with COPD prescribed such medicine during the assessment period.

The percentage of COPD patients who admitted hospital was analyzed. COPD admission was defined by the presence of ICD-10 codes J43-44 (except J43.0) for primary or first subsidiary diagnosis in the claim data of admission. All admissions regardless of hospital type were calculated.

Outpatient medical care expenses were calculated by adding up all the costs of the COPD claim data. Medical expenses by COPD was defined by the presence of ICD-10 codes J43-44 (except J43.0) for primary or first subsidiary diagnosis in the claim data. It includes costs for medical examination and consultation during the outpatient visit. Cost for medication was not included.

Medical institutions were categorized as tertiary, general, local, or convalescent hospitals; they were also classified as primary healthcare clinics, public health centers, branch offices of public health centers, or county hospitals. Tertiary hospitals were defined as hospitals that provide specialized medical services to patients with severe diseases. General hospitals were defined as hospitals with more than 100 beds and more than either seven or nine medical specialties. Local hospitals were defined as centers with more than 30 beds. Convalescent hospitals provided principally convalescent services. Primary healthcare clinics were defined as medical centers with less than 30 beds, providing (principally) primary care. A public health center was a center established by local government. Branches of such centers covered smaller regions. A county hospital was a public health center that met the criteria for a hospital (18). The Korean Won (KRW)-USD (\$) exchange rate was that of 15 September 2019 ( $\$$ US1=1,194.5 KRW).

The study protocol was approved by the ethics committee of Konkuk University Hospital (no. KUH1010928). The requirement for informed consent was waived because the work was retrospective in nature and all data were anonymized.

\section{Results}

The numbers of patients assessed were 141,782, 142,790, and 143,339 in years 1,2 , and 3 , respectively. The numbers of medical care institutions assessed were 6,691, 6,722, and 6,470 in years 1,2 , and 3, respectively. In years 1 and 2, the numbers were highest for general hospitals, followed by primary healthcare clinics and tertiary hospitals. In year 3, the number was highest for general hospitals, followed by tertiary hospitals and primary healthcare clinics (Table 1 and Figure 1).

In year 3, there were 106,664 (74.4\%) men with COPD and 36,675 (25.6\%) women with COPD. Most patients were aged $60-80$ years (Figure 2). There were 43 tertiary hospitals $(0.06 \%)$ among the 6,470 medical care institutions. Of all institutions, $81.5 \%(5,275)$ were primary healthcare clinics. Thirty-six of the 43 tertiary hospitals $(83.7 \%)$ each treated more than 500 patients with COPD. In contrast, more than half of all local hospitals (58.2\%), primary healthcare clinics $(82.7 \%)$, and convalescent hospitals $(97.3 \%)$ each treated fewer than 10 patients.

The each PFT implementation rate was $58.7 \%, 62.5 \%$, and $67.9 \%$ in years 1,2 , and 3 , respectively. These rates were highest in tertiary hospitals, followed by general hospitals, local hospitals, and primary healthcare clinics. In year 3 , the rates were $86.5 \%$ in tertiary hospitals, $74.0 \%$ in general hospitals, $53.5 \%$ in local hospitals, $46.0 \%$ in county hospitals, and $45.0 \%$ in primary healthcare clinics (Figure 3). The proportions of institutions exhibiting PFT implementation rates $>70.0 \%$ were $95.4 \%$ (tertiary hospitals), $48.1 \%$ (general hospitals), $30.7 \%$ (local hospitals), and $28.4 \%$ (primary healthcare clinics). The revisit rates were $85.5 \%, 92.1 \%$, and $85.0 \%$ in years 1,2 , and 3 , respectively. These rates were highest for general hospitals, followed by local hospitals, tertiary hospitals, and primary healthcare clinics; in year 3 , the respective rates were $87.5 \%, 84.3 \%, 83.0 \%$, and $82.6 \%$ (Figure 4 ).

The inhaled bronchodilator prescription rates were $67.9 \%, 71.2 \%$, and $76.9 \%$ in years 1,2 , and 3 , respectively. These rates were $95.2 \%$ in tertiary hospitals, $84.5 \%$ in 


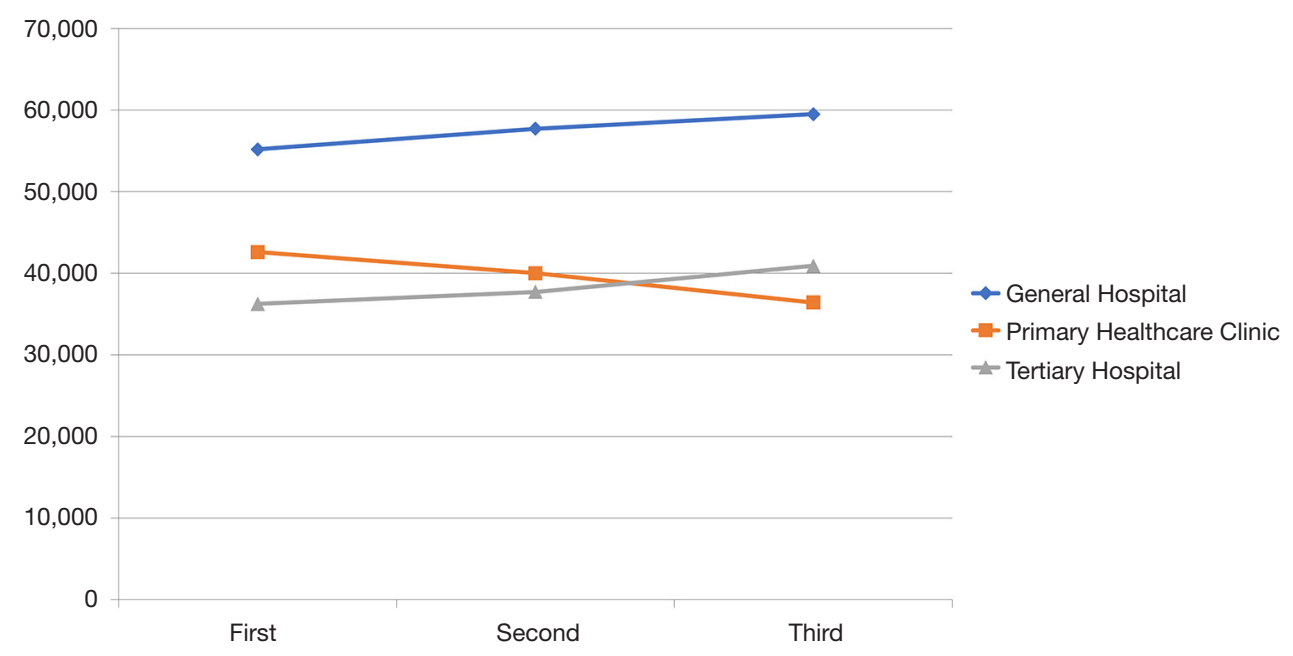

Figure 1 Numbers of patients with chronic obstructive pulmonary disease (COPD) according to treating medical institutions.

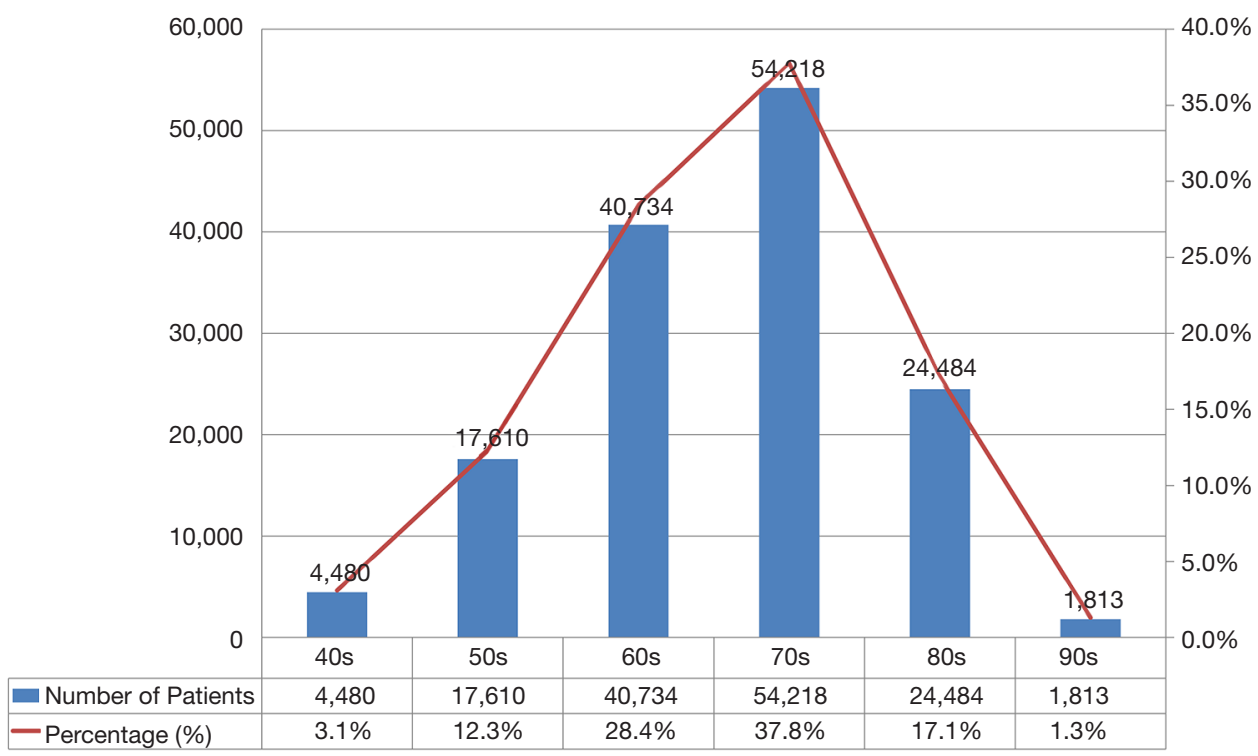

Figure 2 Numbers of patients with chronic obstructive pulmonary disease (COPD) according to age groups.

general hospitals, $66.5 \%$ in county hospitals, $64.2 \%$ in local hospitals, and $46.2 \%$ in primary healthcare clinics (Figure 5). We calculated comprehensive scores by weighting various factors: $40 \%$ for the PFT implementation rate, $20 \%$ for patient revisits, and $40 \%$ for inhaled bronchodilator prescription. The average score was 60.9 , and rose by 2.01 from year 2 to year 3 . The proportions of first-grade institutions receiving scores $>80$ were $13.3 \%, 19.8 \%$, and $23.6 \%$ in years 1,2 , and 3 , respectively. The proportion was highest for tertiary hospitals, followed by general hospitals, primary healthcare clinics, and local hospitals.

Admitted patients were those admitted (to either their usual or other centers) more than once annually for treatment of COPD. The admission rates were $14.2 \%$, $13.1 \%$, and $13.4 \%$ in years 1,2 , and 3 , respectively; in the third year, the rates were $23.2 \%$ to local hospitals, $18.6 \%$ to general hospitals, $13.8 \%$ to tertiary hospitals, and $5.4 \%$ to primary healthcare clinics. In year 3 , the medical care expenses were highest in tertiary hospitals and lowest in convalescent hospitals (Table 2). 


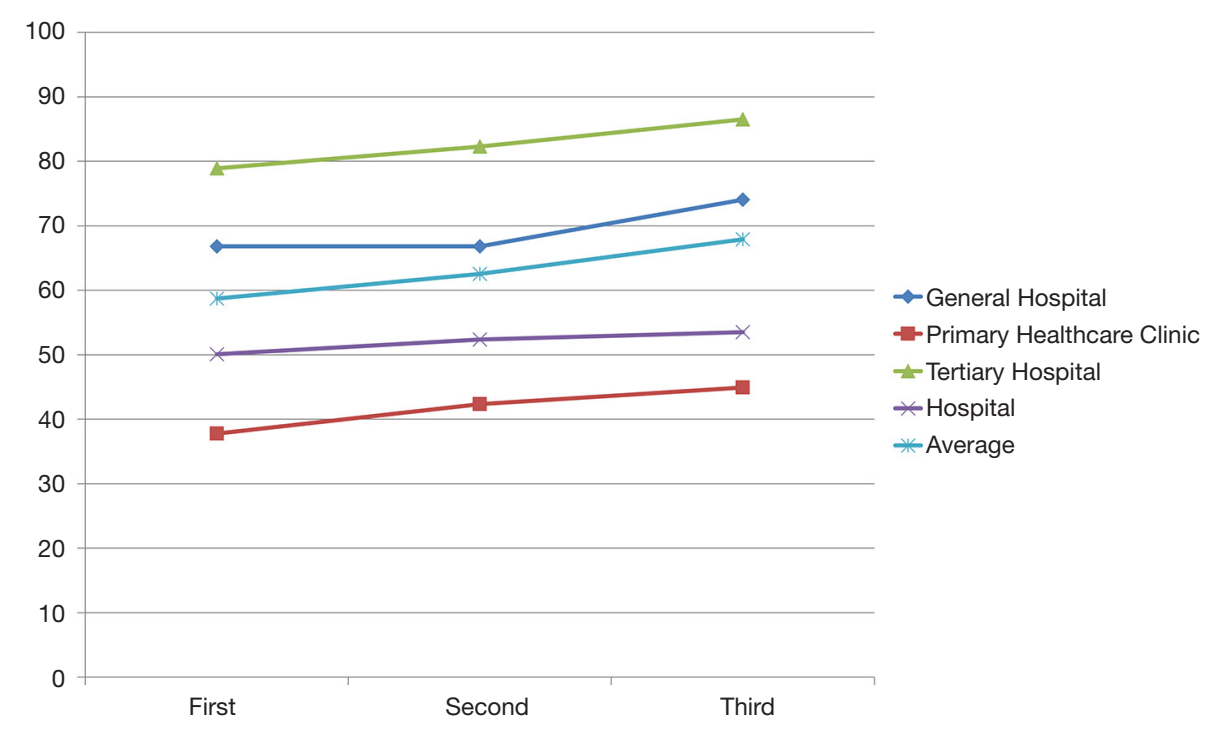

Figure 3 Rates of pulmonary function tests.

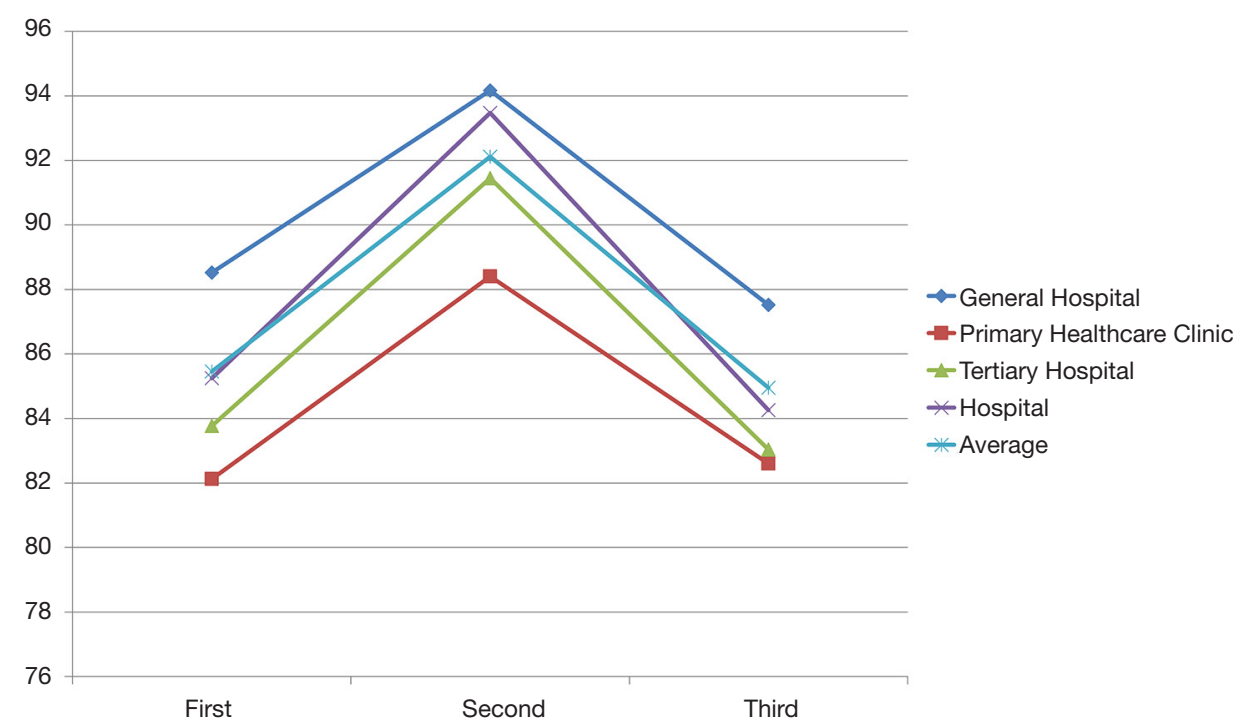

Figure 4 Rates of patient follow-up compliance (revisits).

\section{Discussion}

During the 3 consecutive years of nationwide quality assessment, the PFT test implementation rate improved, as did the rate of inhaled bronchodilator prescriptions. However, the revisit and admission rates did not improve. Most patients with COPD were treated in tertiary hospitals; most patients with asthma received primary medical care from July 2013 to June 2014 (19). The number of patients with COPD was lower than the number of patients with asthma, probably because COPD was underdiagnosed, as revealed by KNHANES II (1). Because COPD is common, primary medical management is important.

Patients who visited tertiary hospitals underwent more PFT than patients who visited primary healthcare clinics, as previously reported for patients with asthma (20). This is a serious problem shared by other Asia-Pacific countries $(12,21)$. Low PFT utilization may result in 


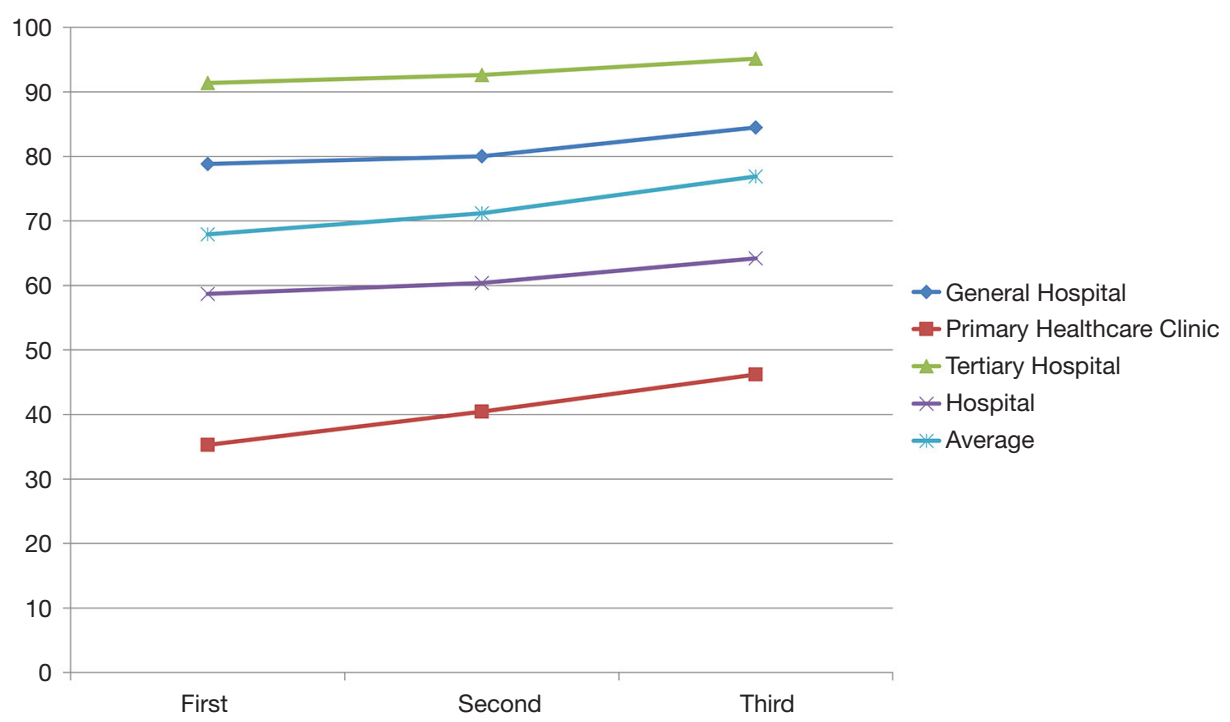

Figure 5 Rates of inhaled bronchodilator prescriptions.

Table 2 Outpatient medical care expenses for patients with chronic obstructive pulmonary disease (COPD)

\begin{tabular}{lccc}
\hline & Number of patients & Medical care expenses (1,000 USD) & Medical care expenses per patient (USD) \\
\hline Total & 143,339 & 16,078 & 112.172 \\
Tertiary Hospital & 40,911 & 5,600 & 136.878 \\
General Hospital & 59,501 & 6,664 & 111.997 \\
Hospital & 10,993 & 1,021 & 92.839 \\
Primary Healthcare Clinic & 36,428 & 2,747 & 75.418 \\
Convalescent Hospital & 511 & 28 & 56.412 \\
County Hospital & 224 & 14 & 64.322 \\
\hline
\end{tabular}

COPD underdiagnosis; the PFT is essential. To better manage COPD in Asia, the Asian Pacific Society of Respirology suggested that the PFT rate could be improved by education of general practitioners, as well as by governmental interventions (e.g., the present study) (12). HIRA monitors the management of all patients with COPD; quality assessment should increase the PFT rate. Inhaled bronchodilators are essential for symptom management and symptom reduction/prevention. Inhaler use is low in South Korea, as previously reported for patients with asthma (18). A similar situation was described in other Asian countries, perhaps due to relative poverty, a cultural preference for oral medication, and a reluctance to use inhalers $(12,22)$.

Our study had certain limitations. Patients with COPD were defined only by ICD-10 codes and prescription of COPD medication. However, this definition of COPD has been used and validated in several previous NHIRAS studies. Second, we lacked PFT results, smoking histories, and COPD Assessment Test scores. Third, this is a report of quality assessment and there was no statistical comparison between groups. No comparison has been performed in quality assessment program. Finally, we only analyzed the revisit rate of the enrolled patients who visited the same medical care institution. However, some patients may select different medical care institutions for further treatment. This may lead to bias.

In spite of above limitations, this is the first nationwide quality assessment of COPD globally. We evaluated approximately 140,000 patients and 6,500 medical 
institutions during each of the three assessment periods. Certain indices improved over time. These results will serve as a reference for other Asian countries that strive to manage COPD. The findings show that nationwide quality assessment is valuable.

\section{Conclusions}

During 3 years of nationwide quality assessment, the rates of PFT implementation and inhaled bronchodilator prescriptions improved.

\section{Acknowledgments}

This study was supported by the Joint Project on Quality Assessment Research of HIRA.

Funding: None.

\section{Footnote}

Data Sharing Statement: Available at http://dx. doi. org/10. 21037/jtd-20-905

Peer Review File: Available at http://dx. doi. org/10.21037/ jtd-20-905

Conflicts of Interest: All authors have completed the ICMJE uniform disclosure form (available at http://dx. doi. org/10. 21037/jtd-20-905). Prof Rhee serves as an unpaid editorial board member of Journal of Thoracic Disease. The authors have no other conflicts of interest to declare.

Ethical Statement: The authors are accountable for all aspects of the work in ensuring that questions related to the accuracy or integrity of any part of the work are appropriately investigated and resolved. The study was conducted in accordance with the Declaration of Helsinki (as revised in 2013). To protect their confidentiality, all patients were assigned and anonymous identification code in the HIRA database that prevented the authors from identifying them. The study was approved by the Institutional Review Board of Konkuk University Hospital (No. KUH1010928). The requirement for informed consent was waived because the work was retrospective in nature and all data were anonymized.

Open Access Statement: This is an Open Access article distributed in accordance with the Creative Commons
Attribution-NonCommercial-NoDerivs 4.0 International License (CC BY-NC-ND 4.0), which permits the noncommercial replication and distribution of the article with the strict proviso that no changes or edits are made and the original work is properly cited (including links to both the formal publication through the relevant DOI and the license). See: https://creativecommons.org/licenses/by-nc-nd/4.0/.

\section{References}

1. Yoo KH, Kim YS, Sheen SS, et al. Prevalence of chronic obstructive pulmonary disease in Korea: the fourth Korean National Health and Nutrition Examination Survey, 2008. Respirology 2011;16:659-65.

2. Kim C, Kim Y, Yang D-W, et al. Direct and Indirect Costs of Chronic Obstructive Pulmonary Disease in Korea. Tuberc Respir Dis (Seoul) 2019;82:27-34.

3. Statistics Korea. The cause of death in South Korea. 2018. Accessed 1-Aug 2020. Available online: http://kostat.go.kr/ portal/korea/kor_nw/1/6/2/index.board

4. Kim C, Yoo KH, Rhee CK, et al. Health care use and economic burden of patients with diagnosed chronic obstructive pulmonary disease in Korea. Int J Tuberc Lung Dis 2014;18:737-43.

5. Kim JA, Lim MK, Kim K, et al. Adherence to Inhaled Medications and its Effect on Healthcare Utilization and Costs Among High-Grade Chronic Obstructive Pulmonary Disease Patients. Clin Drug Investig 2018;38:333-40.

6. OECD. Health at a Glance 2017. 2017.

7. Kim J, Lee JH, Kim Y, et al. Association between chronic obstructive pulmonary disease and gastroesophageal reflux disease: a national cross-sectional cohort study. BMC Pulm Med 2013;13:51.

8. Kim J, Rhee CK, Yoo KH, et al. The health care burden of high grade chronic obstructive pulmonary disease in Korea: analysis of the Korean Health Insurance Review and Assessment Service data. Int J Chron Obstruct Pulmon Dis 2013;8:561-8.

9. Kim J, Kim K, Kim Y, et al. The association between inhaled long-acting bronchodilators and less in-hospital care in newly-diagnosed COPD patients. Respir Med 2014;108:153-61.

10. Rhee CK, Yoon HK, Yoo KH, et al. Medical utilization and cost in patients with overlap syndrome of chronic obstructive pulmonary disease and asthma. COPD 2014;11:163-70.

11. Lee J, Lee JH, Kim JA, et al. Trend of cost and utilization 
of COPD medication in Korea. Int J Chron Obstruct Pulmon Dis 2016;12:27-33.

12. Rhee CK, Chau NQ, Yunus F, et al. Management of COPD in Asia: A position statement of the Asian Pacific Society of Respirology. Respirology 2019;24:1018-25.

13. Park SC, Kim YS, Kang YA, et al. Hemoglobin and mortality in patients with COPD: a nationwide population-based cohort study. Int J Chron Obstruct Pulmon Dis 2018;13:1599-605.

14. Park SC, Kim DW, Park EC, et al. Mortality of patients with chronic obstructive pulmonary disease: a nationwide population based cohort study. Korean J Intern Med 2019;34:1272-8.

15. Park HJ, Byun MK, Kim T, et al. Frequent Outpatient Visits Prevent Exacerbation of Chronic Obstructive Pulmonary Disease. Sci Rep 2020;10:6049.

16. Park HY, Kang D, Lee H, et al. Impact of chronic obstructive pulmonary disease on mortality: A large national cohort study. Respirology 2020;25:726-34.

17. Park HY, Kang D, Shin SH, et al. Chronic obstructive

Cite this article as: Kim KY, Yoo KH, Choi HS, Kim BY, Ahn SI, Jo YU, Rhee CK. Nationwide quality assessment of treatment for chronic obstructive pulmonary disease. J Thorac Dis 2020;12(12):7174-7181. doi: 10.21037/jtd-20-905 pulmonary disease and lung cancer incidence in never smokers: a cohort study. Thorax 2020;75:506-9.

18. Choi JY, Yoon HK, Lee JH, et al. Nationwide use of inhaled corticosteroids by South Korean asthma patients: an examination of the Health Insurance Review and Service database. J Thorac Dis 2018;10:5405-13.

19. Choi JY, Yoon HK, Lee JH, et al. Current status of asthma care in South Korea: nationwide the Health Insurance Review and Assessment Service database. J Thorac Dis 2017;9:3208-14.

20. Choi JY, Yoon HK, Lee JH, et al. Nationwide pulmonary function test rates in South Korean asthma patients. J Thorac Dis 2018;10:4360-7.

21. Lim S, Lam DC, Muttalif AR, et al. Impact of chronic obstructive pulmonary disease (COPD) in the Asia-Pacific region: the EPIC Asia population-based survey. Asia Pac Fam Med 2015;14:4.

22. Dong YH, Hsu CL, Li YY, et al. Bronchodilators use in patients with COPD. Int J Chron Obstruct Pulmon Dis 2015;10:1769-79. 